RANN were heard, has been a cautious welcome. But President Carter is known to be carrying out assessment of the effectiveness of the current organisation of research funding. A $\$ 4$ million programme providing basic support for university research, known as "basic research stability grants", has already been "impounded" by the President from the NSF's 1978 budget prior to the outcome of this assessment.

ASRA will therefore no doubt receive close attention from both the House and the Senate during the hearings on the President's proposals for the science budget, due to take place in March.

David Dickson

\title{
Shcharanskii may soon be brought to trial -without a lawyer
}

The US National Academy of Sciences has made an unprecedented demand for permission to send a legal observer to the forthcoming trial of Anatolii Shcharanskii, the Soviet cybernetician, who, until his arrest last March acted as spokesman for the unofficial 'Sunday Seminars' and was an active member of the Moscow Helsinki Monitoring Group.

Since his arrest, Shcharanskii has been held incommunicado, pending investigation on charges amounting to treason. The official 9-months investigation period expired in December, whereupon the investigating officers requested and were granted an extension of six months. Nevertheless, Shcharanskii's mother has now been told that she should find a lawyer for her son, not later than Friday, January 13, 1978 -a somewhat ironic instruction since already at least 30 Moscow lawyers have refused to act in his defence.

According to a TASS statement of 22 December, the charge against Shcharanskii is that of giving assistance to a foreign State by systematically supplying his 'masters' with slanderous information about the Soviet Union, which was then actively used for ideological diversion against the Soviet Union, and supplying to the West information about Soviet enterprises and institutions, data which constituted official secrets. Already quasijuridical 'hearings' in Stockholm, New York, Paris and London, have presented a considerable bulk of evidence in rebuttal of these charges. While the publicity value of such moves may be considerable, the comment of Literaturnaya Gazeta that it is only a court which can determine Shcharanskii's innocence or guilt and that it is not for US lawyers to maintain law and order in the USSR does have a certain justification. The move of the NAS, in requesting the presence of an observer at the trial, is possibly proving more difficult to answer, since, although the handdelivered letter was accepted by the Soviet Embassy in Washington, to date no answer has been received-a standard Soviet practice in dealing with embarrassing requests from abroad.

The NAS appeal was made by its

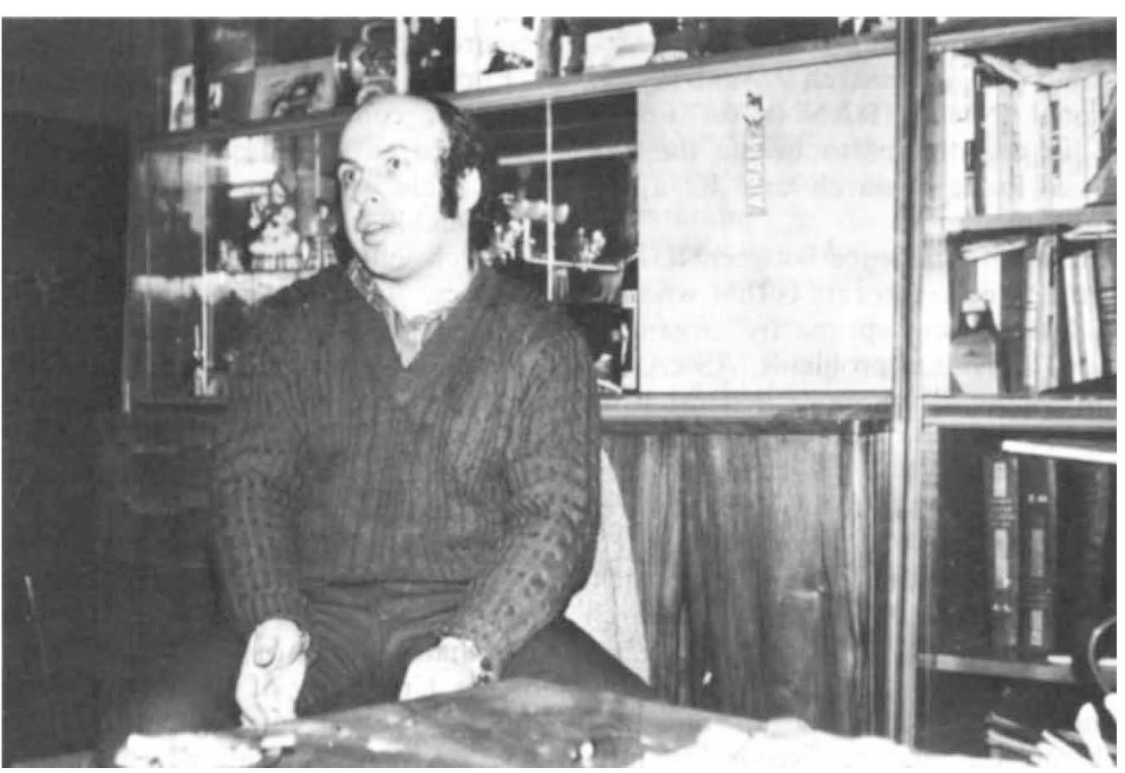

Anatolii Shcharanskii : held incommunicado

Committee on Human Rights, which was founded in 1976 at the requests of the grass-roots membership of the Academy. The Committee includes some 50 members of the Academy and in all, out of a membership of 1,200, over 350 members have done active work on behalf of dissident or imprisoned scientists. To date, their most notable success has been the release of the Argentinian Juan Carlos Gallardo, although they freely admit that the credit for this must go not to the NAS alone but to the whole human rights movement.

The Shcharanskii appeal noted the "widespread reaction . . . and grave concern" among Shcharanskii's colleagues in the USA and elsewhere, and suggested that further action against him would "severely damage scientific interactions with the USSR". This is not an idle threat-already the American Association of Computing $\mathrm{Ma}$ chinery has threatened to break off exchange relations with the Soviet Union over the Shcharanskii case. The Human Rights Committee of the NAS acts essentially as a mouthpiece of membership pressure. If there should be a widespread demand for a severance or suspension of such agreements (and with more than a quarter of the membership actively involved in human rights activities, this is by no means impossible), the implications would be considerable. Although there exists a direct intergovernmental scientific exchange programme (established by the Nixon-Brezhnev talks of 1972), the exchange agreement between the Soviet and US Academies is a much older one (dating from 1959) and is both extensive and prestigious.

The NAS appeal is only one expression of the unprecedented concern which the Shcharanskii case has evoked. A number of factors are involved. One is, of course, the gravity of the charges. The choice of these charges, and suggestion of CIA involvement may in itself be a result of human rights action in the West. A few years ago, when intervention by such bodies as Amnesty International on behalf of dissidents became embarrassing, certain attempts were made to produce criminal charges so as to put the case outside Amnesty competence. Thus the refusnik physicist Viktor Pol'skii was accused of dangerous driving and manslaughter. The human rights activists promptly reformulated their terms of reference to include such cases, so that 
from this point of view, the Shcharanskji case may be envisaged as the next move in a grim kind of human chess. Incidentally, the charge of disclosing state secrets is particularly ironic, since on graduation Shcharanskii carefully avoided taking a post where he might be exposed to classified information, which could hinder his chances of emigrating to Israel. Similarly, the Kiev physicist Vladimir Kislik, against whom, it is feared, similar charges may be in preparation is specifically accused of illegally sending abroad a scientific paper for publication. Not only is the information contained in it not secret; according to a western referee, the subject matter is so well known that he would not himself recommend publication.

Shcharanskii is somewhat of an exception among the refusniks, who, while awaiting their visas for Israel generally try to avoid dissident politics. The usual refusnik polciy, as explained to Nature by Mark Azbel, former leader of the seminar is to avoid any confusion of the two issues, lest the

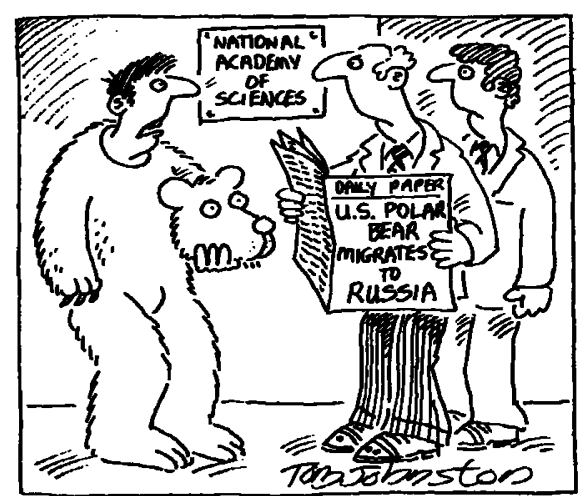

"Gee prof, there must be easier ways of getting in to observe the Shcharanskii trial"'

would-be emigres be accused of subversion and the dissidents of Zionism. Whether such a distinction is possible is a moot point, since the Soviet authorities themselves seem bent on confusing it, by claiming, for example, that Sakharov is "really a Jew called Zuckermann". Shcharanskii, however, during his time in 'limbo' took an active interest in the Helsinki monitor- ing group. Thus his arrest can be seen either as part of the renewed pressure on the Seminar, the 70 hard-core members of which are now being subjected to increasing surveillance including the use of cars with special listening devices, or as part of the campaign against the Helsinki monitoring groups two of which (in Ukraine and Armenia) had several members arrested over the (Western) Christmas holidays, when, it was presumably hoped, the news might pass unnoticed abroad.

From its very beginning, the Soviet human rights movement has been predominantly a movement of scientists, and this fact has undoubtedly contributed to an increasing concern about Western scientists with such problems. To date, except in the special case of psychiatry, where misuse of professional knowledge for political ends was involved, there has so far been no threat that protest abroad would lead to the severing of scientific relations. How far such sanctions will go in defence of Shcharanskii remains to be seen.

Vera Rich

\section{Tory attacks energy gap forecasting- and the fast breeder}

A British Conservative MP has attacked the hypothesis that there will be an 'energy gap' in the UK towards the end of this century, and questioned the economic sense of a commitment to a large programme of fast breeder reactors. The MP, Mr Nigel Forman, is the author of a Conservative Political Centre (CPC) pamphlet published this week titled Towards a more conservative energy policy. The document, while not a formal statement of Conservative Party policy, is according to a CPC spokesman "fairly close to the mainstream of Conservative thinking".

$\mathrm{Mr}$ Forman calls for emphasis on improving the efficiency of the production and distribution of energy, where $30 \%$ of primary energy is wasted, and proposes a flexible energy policy which operates on the demand as well as the supply of energy.

In a refreshing document which seems to verge on the radical rather than the conservative, the MP calls for more research on renewable resources, and for an approach to energy policy which will "liberate it from the requirements of the major vested interests". The conventional wisdom on renewable energy sources "scems to assume that they will make only a limited contribution to the energy supplies of the UK by the year 2000". However the main reason that the predictions are modest "is that until very recently the R\&D effort on nuclear energy, for example, exceeded that on all the renewable resources together by a factor of about 100".

Mr Forman brings his strongest criticism to bear on conventional energy forecasting and on the economics of the fast breeder programme. "It is when the experts begin to foretell the future that the trouble really begins" writes Forman. Undaunted by their predictions of an energy gap he argues that "what we are really being offered is little more than predictions of a change from a brief period of energy self-sufficiency in the 1980s and 1990s to a renewed period of energy import dependencemainly for liquid hydrocarbons-at a time when the real price of energy is likely to be significantly higher than it is today. The threat, if there is one, is therefore to the prospect of continued exponential growth of final energy demand .... it is not, nor need ever be, a threat to a society with improving rates of efficiency in fuel conversion and energy use".

An energy forecast is impossible, says Forman, without making prior political assumptions; and one of those assumptions ought to be that demand can be modified to meet supply.

On reprocessing and the proposed facility at Windscale, $\mathbf{M r}$ Forman argues that "there simply will not be the necessary nuclear fuel throughput from the Continent or elsewhere to justify such a large investment". Reprocessing, in other words, is uneconomic. The same is true of the fast breeder, says the MP, pointing out that the construction of around 20 breeder reactors of $1,300 \mathrm{MW}$ each would cost a total of some $£ 30$ billion. "Simply to postulate such an enormous figure is to underline the foolishness of committing this nation to such a singleminded and excessive expenditure on a form of energy supply which we are unlikely to be able to afford and may not even need".

It may shock them, but with Prime Minister Jim Callaghan bearing down on Energy Minister Tony Benn to make him take a more pro-nuclear line it is beginning to appear that the best thing the Friends of the Earth could do would be to vote Tory.

Robert Walgate

\section{Soviets look after their cosmonauts}

ThF purpose of the Soyuz-Salyut programme is not the carrying out of separate experiments, however unique. In a recent Tass statement, Flight Director Vadim Kravets announced that the ultimate aim is the establishment of a permanent scientific watch in orbit.

Accordingly, much is being done towards cosmonaut comfort and better working conditions, including the installation of a shower in Salyut 6 and the introduction of new semi-rigid space suits for extra-vehicular activity. 